\title{
Application of 2-Trichloromethylbenzimidazole in Analytical Chemistry: A Highly Selective Chromogenic Reagent for Thin-Layer Chromatography and Some Other Analytical Uses
}

\author{
Leszek Konopski and Anna Kiełczewska \\ Analytical Department, Institute of Industrial Organic Chemistry, Annopol 6, 03-236 Warsaw, Poland \\ Correspondence should be addressed to Leszek Konopski, konopski@ipo.waw.pl
}

Received 30 November 2011; Accepted 11 January 2012

Academic Editor: Josep Esteve-Romero

Copyright ( 2012 L. Konopski and A. Kiełczewska. This is an open access article distributed under the Creative Commons Attribution License, which permits unrestricted use, distribution, and reproduction in any medium, provided the original work is properly cited.

2-Trichloromethylbenzimidazole (TCMB) was used as a chromogenic reagent in organic or inorganic analysis, mainly in thin-layer chromatography (TLC). In reactions of TCMB with some heteroaromatic nitrogen containing compounds, such as azines, azoles and benzazoles, a formation of high colored products occurred. For azines, the chromogenic reaction was highly regioselective, since the both adjacent $\alpha$-positions versus the nitrogen atom(s) must not be substituted. A TLC method of detection was developed. Thirty azines, azoles, and benzazoles were detected at the detection limit $10 \mathrm{ng}$ to $1 \mu \mathrm{g}$. This method was also applied for detection of heteroaromatic pesticides, and the attempts to construct active and passive dosimeters for nicotine were made. In a prechromatographic reaction of aromatic $o$-diamines with methyl trichloroacetimidate, TCMB or its derivatives were formed in situ. Followed by TLC and visualization in pyridine vapors, this procedure was applied for detection of $o$ phenylenediamine derivatives. The reaction product of TCMB and pyridine (LI Complex) was identified and fully characterized. Two different reaction mechanisms: with electron deficient basic heteroaromatic compounds, like pyridine, and with more acidic compounds, for example, pyrrole, were discussed. In aqueous solutions, the LI Complex may be also used as a new indicator for complexometric, adsorption and acid-base titration of inorganic compounds.

\section{Introduction}

The synthesis of 2-trichloromethylbenzimidazole (TCMB, 1) was first described in 1967 by Holan and coworkers [1]. Some reactions of this highly reactive compound with different nucleophiles, such as liquid ammonia (with 2-cyanobenzimidazole formation, in a rather unusual transformation of $-\mathrm{CCl}_{3}$ group into $-\mathrm{C} \equiv \mathrm{N}[2]$ ), primary and secondary amines, bifunctional compounds [3], water, alcohols, and thiols [4] were studied by the same team. The only mention concerning reactions of the compound (1) with tertiary aliphatic amines was that some unstable and unidentified compounds are formed [2].

TCMB was a key starting material during preparation the Ph.D. dissertation of Dr. Konopski in early 1970s. One of unsolved issues was purification of this compound, originally crystallized from high-boiling nitrobenzene, what was not convenient. Once during crystallization attempts trying various organic solvents it was unexpectedly found that colorless (1), usually sparingly soluble in most of solvents, did dissolved very easily and underwent a vigorous reaction with pyridine 2 at room temperature. During several seconds the colorless solution became yellow, green, blue, violet, and purple, consecutively, and after about 2 min of the exothermic reaction, an intense amaranth solid precipitated from the pyridine solution. The high-colored product (LI Complex) remained unidentified until 1980s. In this paper, a review of LI Complex and another high-colored product identification and application of this color reaction in several analytical methods for both organic and inorganic compounds has been presented.

\section{TCMB as a High-Colored Chromogenic Agent for TLC of Heteroaromatic Compounds}

2.1. Azines. The reactions of TCMB with different heteroaromatic compounds have been systematically studied by 
TABLE 1: Colors and detection limits of the examined azines visualized with TCMB on TLC plates [5].

\begin{tabular}{|c|c|c|c|}
\hline Compound no. & Azine (common name) & Color (for $1000 \mathrm{ng}$ in spot) & $\begin{array}{l}\text { Detection Limit } \\
\text { LOD (ng) }\end{array}$ \\
\hline 2 & Pyridine & Amaranth & 50 \\
\hline 3 & Pyridazine & Red & 20 \\
\hline 4 & Pyrimidine & Gray-green & 100 \\
\hline 5 & Pyrazine & Yellow & 100 \\
\hline 6 & 3-Metylpyridine ( $\beta$-picoline) & Amaranth-brown & 20 \\
\hline 7 & 4-Metylpyridine ( $\gamma$-picoline) & Ochre-yellow & 20 \\
\hline 8 & 4,4'-Bipyridil & Orange & 10 \\
\hline 9 & 3-Formylpyridine & Ochre-yellow & 20 \\
\hline 10 & 4-Formylpyridine & Ochre-yellow & 20 \\
\hline 11 & 4-Cyanopyridine & Orange & 20 \\
\hline 12 & 4-Aminopyridine & Yellow & 50 \\
\hline 13 & Nicotinic acid (Vitamin PP) & Yellow-green & 10 \\
\hline 14 & Isonicotinic acid & Yellow-green & 10 \\
\hline 15 & Methyl nicotinate & Yellow & 20 \\
\hline 16 & Nicotinamide (Vitamin PP) & Yellow & 20 \\
\hline 17 & $N$-(Hydroxymethylnicotinamide) (Cholamid) & Ochre-yellow & 20 \\
\hline 18 & Isonicotinohydrazide (Isoniazid) & Orange & 20 \\
\hline 19 & Nicotine & Yellow & 20 \\
\hline 20 & 2-Pyrazinecarboxamide & Orange & 20 \\
\hline
\end{tabular}

Konopski and coworkers since 1986. It was found that analogical colored products as with pyridine 2 were formed in the reactions of TCMB with some pyridine derivatives substituted at the 3- and/or 4-positions but with both 2- and 6positions free [5]. Similar reactions with high-colored products formation were observed also for diazines, such as pyridazine 3 , pyrimidine 4 , and pyrazine 5 but always the necessary condition was that both $\alpha$-positions versus at least one nitrogen atom in the azine ring should be unsubstituted [5]. Although the reaction occurred already at room temperature (RT), it was observed that it may be accelerated by heating to $100-150^{\circ} \mathrm{C}$. This reaction was used for selective detection of some pyridine and diazines derivative unsubstituted in both $\alpha$-positions on thin-layer chromatographic (TLC) plates [5]. Standard Merck aluminum plates coated with Silicagel (Merck) and a solvent system appropriate for the detected compounds were used. The developed plates were dried on air, sprayed with 1\% TCMB acetone solution, and placed in a laboratory drier for $1 \mathrm{~min}$ at $150^{\circ} \mathrm{C}$, giving intensively colored spots with a decent low limit of detection (LOD) of 10$100 \mathrm{ng}$ (Table 1).

Only azines with both 2- and 6-positions free versus at least one nitrogen atom in the azine ring produced highcolored compounds when treated with TCMB, probably due to steric hindrance effect. For the same reasons, there was no color reaction with quinoline, isoquinoline, quinine, and 1,10-phenantroline as well. 4-Hydroxypyridine did not react because the tautomeric pyridone was probably formed in solution [5].

2.2. Azoles and Benzazoles. In the same manner, the chromogenic reactions of (1) with five-membered heteroaromatic rings containing 1 to 4 nitrogen atoms without [6] or with [7] condensed benzene ring and their application for detection of these compounds on TLC plates were also described.

The following heteroaromatic nitrogen containing compounds with 5 -member ring gave no chromogenic reaction after spraying with $1 \%$ TCMB acetone solution on TLC plates: 1-methyl pyrrole, pyrazole, 1- and 3-methyl pyrazole, imidazole, 4-methyl and 4-nitroimidazole, 1-methyl-(1H)1,2,3-triazole, 2-methyl-(2H)-1,2,3-triazole, 1,2,4-triazole, 1-methyl- and 3-nitro-( $1 H)$-1,2,4-triazole, $(1 H)$-1,2,4-triazole-3-thiol, 1-methyl-( $1 H)$ - and 2-methyl-(2-H)-tetrazole, (1H)-1,2,3,4-tetrazole-5thiol [6], oxazole, isoxazole, 4-methyloxazole, thiazole, isothiazole, 2-methylbenzothiazole, 2mercaptomethylbenzothiazole, 1methylindole, benzimidazole, benzotriazole, 1-methylbenzotriazole, and 2-methylbenzotriazole [7].

It was found that probably two different reaction mechanisms took place [8].

(a) For azoles without three vicinal nitrogen atoms in the heteroaromatic ring and/or a weakly acid $\mathrm{NH}$ group, a chromogenic reaction I [6] analogous to that described for the azines [5] seems to occur. The necessary conditions for this reaction to occur are that (i) both $\alpha$-positions should be unsubstituted with respect to the basic tertiary nitrogen atom $-\mathrm{N}=$ and (ii) the labile hydrogen atom at the weakly acidic secondary nitrogen NH should be protected by substitution with an alkyl, for example, in the imidazole moiety, 1-methylimidazole 22, or 1ethylimidazole 23.

(b) For the compounds with a more acidic hydrogen in the $\mathrm{NH}$ group, such as pyrrole 21 , or with three or more contiguous nitrogen atoms in the azole ring, as 
TABLE 2: Colors and detection limits of the examined azoles [6] and benzazoles [7] visualized with TCMB on TLC plates.

\begin{tabular}{|c|c|c|c|c|}
\hline Compound no. & Azole & $\begin{array}{c}\text { Color } \\
\text { (for } 10 \mu \mathrm{g} \text { in spot) }\end{array}$ & $\begin{array}{l}\text { Detection limit } \\
\text { (LOD, ng) }\end{array}$ & $\begin{array}{c}\text { Mechanism of } \\
\text { chromogenic reaction }\end{array}$ \\
\hline 21 & Pyrrole & Brown & 500 & II \\
\hline 22 & 1-Methylimidazole & Brown-yellow & 10000 & I \\
\hline 23 & 1-Ethylimidazole & Yellow & 5000 & I \\
\hline 24 & 1,2,3-Triazole & Brown & 50 & II \\
\hline 25 & 4-Methyl-(4H)-1,2,4-triazole & Yellow & 1000 & II \\
\hline 26 & Tetrazole & Khaki & 1000 & II \\
\hline 27 & Benzotriazole & Yellow & 300 & II \\
\hline 28 & Indole & Amaranth & 100 & II \\
\hline 29 & Benzothiazole & Grey & 1000 & II \\
\hline 30 & 2-Mercaptobenzothiazole & Brown & 500 & II \\
\hline
\end{tabular}

in 1,2,3-triazole 24, 4-methyl-(4H)-1,2,4-triazole $\mathbf{2 5}$ and tetrazole 26 , the previous reaction did not take place or could be a side reaction, but another mechanism - chromogenic reaction II-might be observed. Pyrrole 21 and 1,2,3-triazole 24 unexpectedly reacted quickly even at room temperature, whereas 1-methylpyrrole and both 1- and 2-methyl-1,2,3triazoles did not form any intensively colored product with TCMB. In the reaction of TCMB with an excess of 1,2,3-triazole $\mathbf{2 5}$ as a solvent, the formation of a brown product and evolution of nitrogen were observed. No volatile products except unreacted starting materials were found. Probably the decomposition of triazole 25 and TCMB occurs with evolution of nitrogen and the formation of unidentified products [8].

(c) The same type of mechanism of chromogenic reaction II was observed in reactions of TCMB 1 with nitrogen containing heteroaromatic compounds with the condensed benzene ring [7]. It was found the high-color reactions occurred with benzo- homologues of 1,2,3-triazole and pyrrole-benzotriazole 27 and indole 28, as well as with benzothiazole 29 and 2mercaptobenzothiazole 30; most probably the second mechanism took place with elimination of acetylene, nitrogen, carbon monosulfide, and disulfide, respectively [8] (see Table 2).

\subsection{Structure of LI Complex and Mechanisms of Chromogenic} Reactions. We have identified the structure of the main component 31 of the LI Complex, the amaranth product of the reaction of TCMB 1 with pyridine 2 . It was a complex mixture of highly polar, intensively colored, and unstable products. The crude LI Complex was purified by preparative TLC on precoated polyamide aluminum sheets. The main amaranth compound $\mathbf{3 1}$ was characterized using the following analytical and spectral evidence: elemental analysis, EI MS, HR EI MS, FD MS, ${ }^{1} \mathrm{H}$ NMR, IR, UV-VIS [9], and ${ }^{13} \mathrm{C}$ NMR [8]. The deuterium labelled octadeuterated compound 31-d $\mathbf{d}_{8}$ was also obtained when the chromogenic reaction was carried out with pyridine- $d_{5}$. The details are described in the

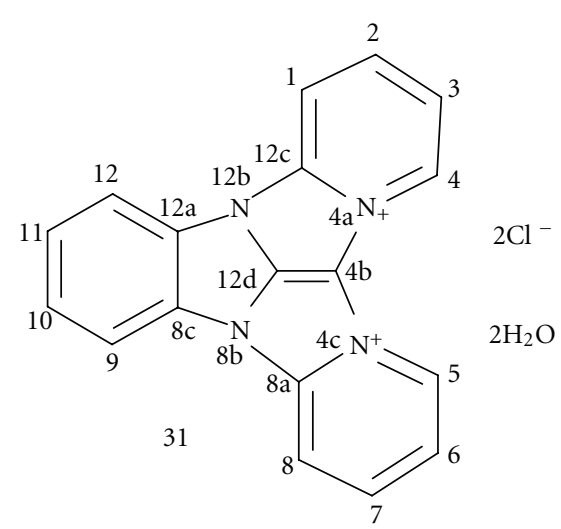

FIGURE 1: The structure of compound 31, the main component of the LI Complex.

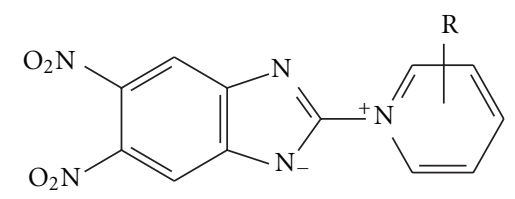

FIGURE 2: Quaternization of 5,6-dinitro-2chlorobenzimidazole 32 by pyridine derivatives producing betaines [10].

paper [9]. It was found the most probable structure of the compound 31 was $4 \mathrm{a}, 4 \mathrm{c}, 8 \mathrm{~b}, 12 \mathrm{~b}$-tetraazadibenzo $[a, f]$ indano $[1,2,3-c d]$ pentalene-4a,4c-diinium dichloride dihydrate (IUPAC) or $8 \mathrm{~b}, 12 \mathrm{~b}$-diaza-4a,4c-diazoniadibenzo [2,3:4,5] pentaleno $[1,6-a b]$ indene dichloride dihydrate (CAS); CAS RN [127024-68-4] (Figure 1).

In the literature, there are only few references concerning this type of reaction. Postovskii et al. [10] described quaternization of 5,6-dinitro-2-chlorobenzimidazole 32 in boiling by pyridine (2) and 3- or 4-picolines receiving yellow betaines after elimination of hydrochloric acid (Figure 2). However, the reaction conditions were substantially more drastic (boiling heterocyclic amine, $1 \mathrm{~h}$ ) than for TCMB (room temperature, $2 \mathrm{~min}$ ). Moreover, the chlorine atom in 32 was much more mobile due to presence of nitro groups in 


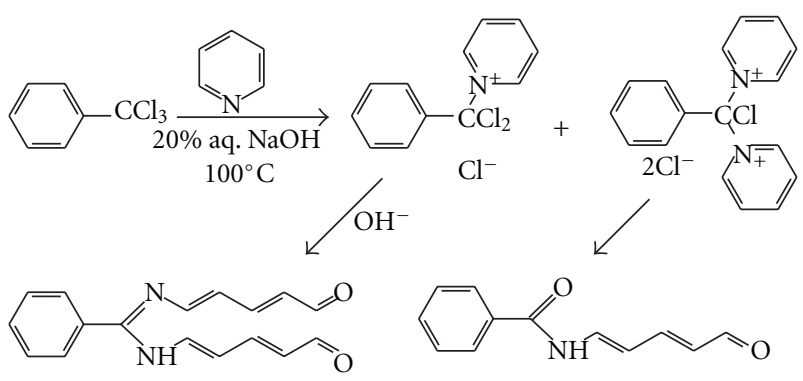

Figure 3: The Fujiwara reaction mechanism [11, 12].

the benzene ring. Similarly to examined reaction of TCMB and picolines, 2-picoline did not react $[8,10]$.

Kyoyetsuro Fujiwara was a Japanese POW in Germany during the WW I, and in 1916 the Fujiwara reaction [11] taking place between $\alpha, \alpha, \alpha$-trichlorotoluene 33 and pyridine 2 in rather drastic conditions (20\% aqueous sodium hydroxide at $100^{\circ} \mathrm{C}$ ) was first described. Two high-colored products, yellow and red, are formed (Figure 3). Reaction was extremely sensitive. The Fujiwara reaction application was reviewed $[7,8,11,12]$.

However, the conditions of the reaction of TCMB with pyridine were very mild and its mechanism and structures of obtained products were different.

Thus, it was found that probably two different reaction mechanisms took place [8]:

(i) with electron deficient basic heterocyclic compounds as azines, for example, pyridine (type $\mathbf{A}$ );

(ii) with heteroaromatic compounds containing acid $\mathrm{NH}$ group as azoles, for example, a benzazole (type $\mathbf{B}$ ).

(A) For the electron deficient basic heteroaromatic compounds without acid $\mathrm{N}-\mathrm{H}$ group or when this group is protected, and when at least one tertiary nitrogen $=\mathrm{N}$-atom without substituents at two adjacent carbon atoms is present in the ring, such as pyridine, diazines (pyridazine, pyrimidine and pyrazine), $N$-substituted imidazole, and 4 -substituted 1,2,4-triazole derivatives, the following mechanism of the compound 31 formation seems to be the most probable (mechanism $\mathbf{A}$, with pyridine $\mathbf{2}$ as an exemplary heterocyclic compound, Figure 4).

The obtained polycyclic diinium compound $\mathbf{3 1}$ is stabilized by the intramolecular charge delocalization (Figure 5).

However, in the ${ }^{13} \mathrm{C}$ NMR spectrum 18 separated carbon signals can be observed. It shows that the molecule is twisted, the carbons in both pyridinium rings are not equivalent, and the asymmetric resonance hybrids $31 \mathrm{c}$ and $\mathbf{3 1} \mathbf{d}$ have a large contribution in the real molecule structure. Additionally, the positive charges localization at two relatively closed nitrogen atoms, as in the structures $\mathbf{3 1 a}$ and $\mathbf{3 1} \mathbf{b}$, seems to be less favorable than in the structures $31 \mathbf{c}$ and $31 \mathbf{d}$, where the distance between charged atoms is longer.

Since there is a partial positive charge at the $\alpha$ - and $\gamma$-carbon atoms in the pyridinium cation $c$, the nucleophillic attack of the electron pairs in its di-imine mesomeric form $d$ at an $\alpha$-carbon in each pyridinium ring and the dihydro- pyridine intermediate $e$ formation was found much more probable than the formation of a new $\mathrm{C}-\mathrm{C}$ bond and formation of the compound 31e (Figure 6).

The reaction product analysis and the ionic chlorine presence [9] let to exclude the possibilities of pyridine ring cleavage and the conjugated polyenes formation in Fujiwara reaction $[11,12]$ as well as betaine products of the reactions of 5,6-dinitro-2-chlorobenzimidazole (32) with pyridine derivatives [9]. The reaction precondition is the absence of any substituent at any carbon atom adjacent to the nitrogen. However, the second adjacent $\alpha$-position must be also free, perhaps due to steric reasons, most probably during the intermediates $a$ and $b$ formation. The dehydrogenation of intermediate $e$ was necessary for the compound $\mathbf{3 1}$ formation. The most probable seems to be rearomatization of dihydropyridine $e$ by double 1,3-hydride shift giving the intermediate $f$. In the literature, it was not found any similar examples of intramolecular 1,3-hydride transfer in such heterocyclic systems, but hydride ion transfer is proved to be typical for reductions by dihydropyridines [13]. The last step was aromatization of $f$ into the final product 31 . It was observed that the dehydrogenation of $f$ is due mainly to oxidation by atmospheric oxygen, since in the atmosphere of an inert gas, such as argon, the reaction of TCMB with pyridine occurs much more slowly. However, other oxidation mechanisms should not be excluded, for example, the oxidative aromatization as it was found in last stage of the Skraup quinoline synthesis [14].

(B) For the compounds with a more acidic hydrogen in the $\mathrm{N}-\mathrm{H}$ group, such as pyrrole (21) and indole (28) or with three or more contiguous nitrogen atoms in the azole ring as benzotriazole (27), 1,2,3-triazole (24), and tetrazole (26), as well as for benzothiazole 29 and 2 mercaptobenzothiazole (30), another reaction mechanism may be observed (mechanism $\mathbf{B}$, with a benzazole as an exemplary heterocyclic compound, Figure 7).

The necessary reaction condition is the presence of acidic secondary NH group, which reacts with TCMB. In this case the quaternization does not take place, but the substitution followed by the hydrogen chloride abstraction seems to occur, and this acid is neutralized by the amine excess. However, the heterocyclic compound should not be a too weak $\mathrm{N}-\mathrm{H}$ acid; therefore this reaction was not observed with pyrazole, imidazole, 1,2,4-triazole, or benzimidazole.

In the next step, the reaction is favored also by elimination of a stable and volatile molecule leaving the reaction medium; in the cases of 1,2,3-triazole (24), tetrazole (26), and benzotriazole (27), the nitrogen elimination was observed. 2-Mercaptobenzothiazole (30) can eliminate the carbon disulfide molecule from its 2-benzothiazolethione tautomeric form (30a); therefore this compound reacted easily with TCMB, whereas 2-methylbenzothiazole and 2-mercaptomethylbenzothiazole, which do not form any thione tautomers, do not react with TCMB [7]. In next steps, abstraction of another molecule of $\mathrm{HCl}$ and re-cyclization may occur to a structure like $b$, high-colored due to several conjugated double bonds. Then, another hydrogen chloride molecule may be eliminated with one more condensation and formation of structure $c$ or similar, and so forth. 


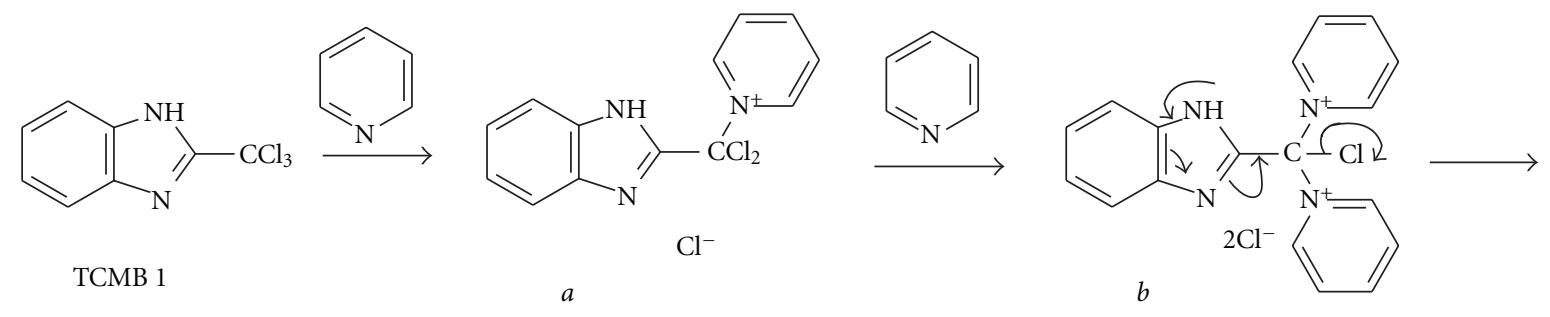

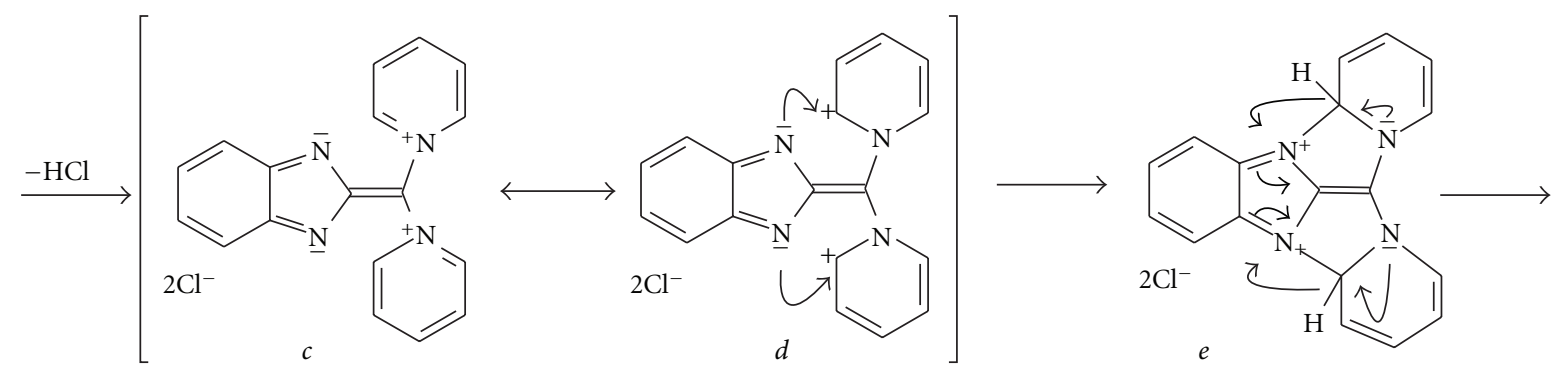

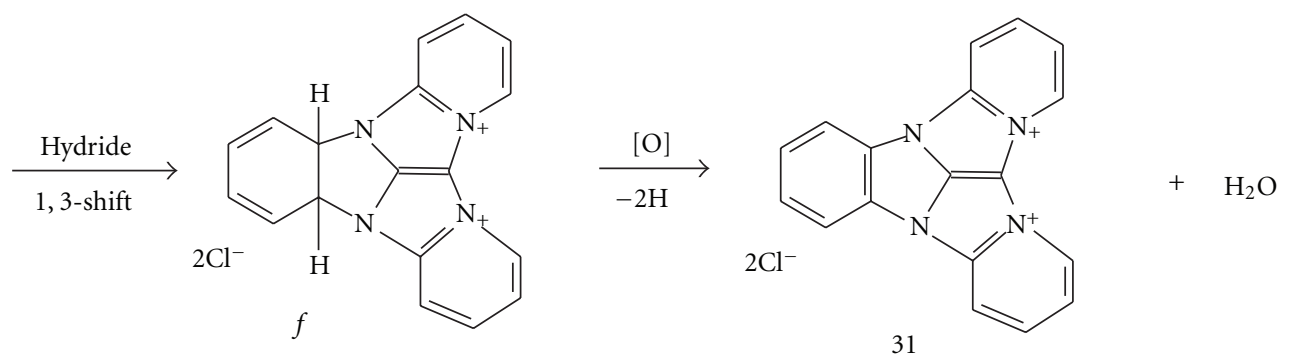

FIGURE 4: Mechanism of chromogenic reaction I (A) of TCMB 1 and pyridine 2 [8].<smiles></smiles>

(a)<smiles></smiles>

31 (b)<smiles></smiles>

(c)

Figure 5: Mesomeric structures of the compound 31, the main component of LI Complex [8]. 


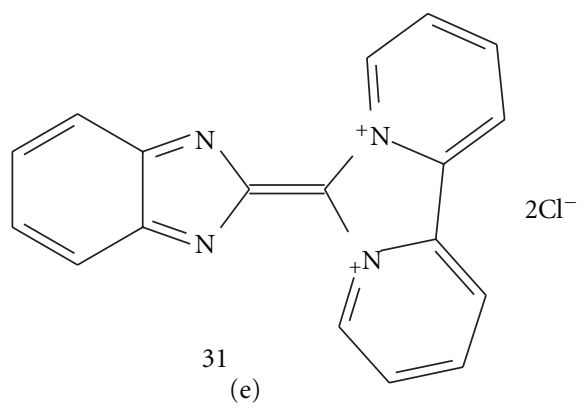

FIGURE 6: 31e, the alternative structure of the compound 31.

The structure of finally obtained dark, unstable, nonvolatile, and probably complex polymeric products of the reactions of the $\mathbf{B}$ type seems to be difficult to identify.

\section{Examples of Application of the TCMB Method for Determination of Organic Compounds on TLC Plates}

3.1. Detection of Aromatic o-Diamines [15]. The classical method of the 2-substituted benzimidazoles synthesis is a condensation of $o$-phenylenediamine and a carboxylic acid with a basic catalyst. However, trichloroacetic acid does not react with $o$-phenylenediamine [1]. That is why in its original preparation, TCMB was synthesized in condensation of methyl trichloroacetimidate (33)[16] and $o$-phenylenediamine (34) in acetic acid at RT [1]. The prechromatographic reaction of aromatic $o$-diamines and commercial methyl trichloroacetimidate (33) with TCMB formation, followed by TLC and visualization in the same dyeing reaction (1015 min in pyridine vapors at RT), was applied for detection of $o$-phenylenediamine (35) and some of its derivatives (Figure 8, Table 3)[15].

Some compounds gave no color reaction using this method of visualisation:

(i) ortho- and peri-naphthylenediamines and 2,3-diaminophenazine, probably for steric reasons;

(ii) $m$ - and $p$-phenylenediamines and aliphatic 1,2-diamines-since the aromatic benzimidazole ring cannot be formed,

(iii) $\mathrm{N}$-methyl-o-phenylenediamine, which probably forms a corresponding 1-methyl-2-trichloromethylbenzimidazole in reaction with methyl trichloroacetimidate, but the heterocyclic obtained does not react subsequently with pyridine and the high-colored LI Complex does not form.

3.2. Determination of Heteroaromatic Pesticides on TLC Plates Using Scanning Spectrodensito-Metry [17, 18]. The method of spraying with $1 \%$ acetone solution of TCMB as a chromogenic agent was applied for visualization for $1 \mathrm{~min}$ at $150^{\circ} \mathrm{C}$ of selected pyridine, pyrimidine, pyrrole, indole, and conazole pesticides on TLC plates. Both chromogenic
TABLE 3: Colors and detection limits of the examined $o$-phenylenediamines on TLC plates [15].

\begin{tabular}{cccc}
\hline $\begin{array}{l}\text { Compound } \\
\text { no. }\end{array}$ & Azole & $\begin{array}{c}\text { Color } \\
\text { (for 1000 ng } \\
\text { in spot) }\end{array}$ & $\begin{array}{c}\text { Detection } \\
\text { limit } \\
\text { (LOD, ng) }\end{array}$ \\
\hline 36 & $\begin{array}{c}\text { o-phenylenediamine } \\
\text { Amaranth- } \\
\text { brown }\end{array}$ & 100 \\
37 & $\begin{array}{c}\text { 3,4-diaminotoluene } \\
\text { 4-nitro-o- } \\
\text { phenylenediamine }\end{array}$ & Brown & 100 \\
\hline
\end{tabular}

reactions I (for 6-member ring heterocycles) and II (for 5member rings) were observed. The detection limit (LOD) was evaluated visually [17] for pesticides 39-46. The quantitation of the thin-layer chromatograms of the other pesticides 47-51 was performed using a scanning spectrodensitometer (Camag TLC Scanner 3) at selected wavelengths 430, 460, and $498 \mathrm{~nm}$; scanning speed was $10 \mathrm{~mm} / \mathrm{s}$ [18]. The relative standard deviation (RSD) values were calculated as level of experimental error using the Student $t$-distribution at a significance level $\alpha=0.05$, and the relative error was less than $15 \%$ (Table 4) [18].

The LODs were calculated as the average from three to five experiments, as the interpolated amount of each compound corresponding to the densitometric peak height equals the tripled average noise level in the detected compound region of the densitogram [18].

Such calculations could not be performed for chromatograms on developed TLC plates where there are no peaks but only spots, and only the smallest still visible spot may be considered as the LOD evaluated visually in this semiquantitative method. So, the full validation of the method for precision, accuracy, reproducibility, and limit of quantification (LOQ) was not performed. The linearity range was not determined as well. However, if the spot area $A$ would be measured using a planimeter, and the amount of determined compound would be equal $c$, the square root of $A$ should be proportional to logarithm of $c$ :

$$
\sqrt{A}=k \cdot \log c+b
$$

where $k$ and $b$ are constants for a given chromatogram.

It was experimentally checked and calculated for fenpiclonil 49 that this equation was really linear, and coefficient of determination $R^{2}$ equals 0.996 .

3.3. Dosimeters for the Nicotine Presence in Air Using the Chromogenic Reaction between TCNB and Nicotine [19]. The possibilities of application of the chromogenic reaction with TCMB for detection of the residual amounts of nicotine in air were studied. LOD of nicotine in this reaction on TLC plates is $20 \mathrm{ng}$ (spot color: yellow).

Passive and active dosimeters were tested. The passive dosimeters were made of glass tubes, $4 \mathrm{~cm}$ length $\times 0.4 \mathrm{~cm}$ i.d. filled with 5 or $10 \%$ TCMB adsorbed on Merck Silicagel $0.2-0.5$ mesh or $50-120$ mesh. Both ends of the tube were protected with a loose plug made of glass cotton. The passive dosimeters were exposed in various locations where 


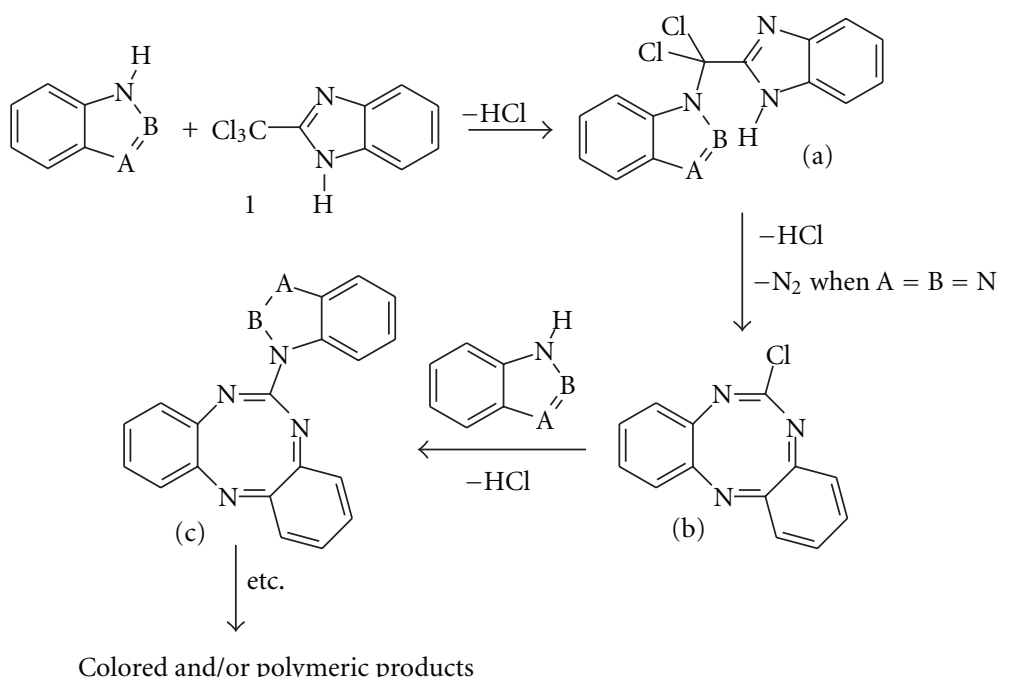

FIGURE 7: Mechanism of chromogenic reaction II (B) of TCMB (1) and a benzazole.

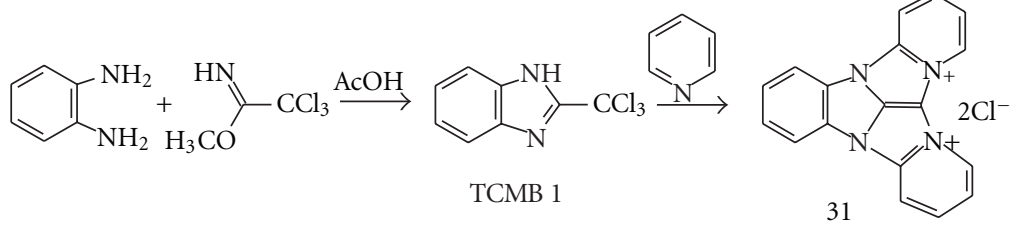

FIgURE 8: Detection of $o$-phenylenediamines on TLC plates.

the cigarettes were smoked intensively (smoking room), moderately (designated areas), or not at all (laboratories). In some tubes, the testing phase got yellowish. Unfortunately, TCMB turned out very sensitive on light and air pollutants and got decomposed to yellow products with color similar to reaction product with nicotine. That is why there was found no essential correlation between presence of tobacco smoke in the examined area and intensity of the color in the testing tube.

Next, the active dosimeters were tested. They had got a similar construction as the passive ones; only the glass tube was longer $(10 \mathrm{~cm})$ and contained 1 to 2 layers of 5$10 \%$ TCMB on Silica. The measurements were carried out by blowing the smoke from a lighted cigarettes with changeable velocity $(0.5-2$ cigarette/min) using just a water aspirator pump. The experiment was carried out with cigarettes of different manufacturers. A compact filter with cellulose wool was indispensable, since the cigarette tar dyed strongly all the tube and the reading was impossible. It was found that independently of the cigarette mark and time of "smoking" ( 0.5 to $2 \mathrm{~min}$ ), after smoking about $1 / 4$ of the cigarette the TCMB on silica in the dosimeter tube changes the color and got yellow. Checking the presence of nicotine in the air respired by a smoking person was also possible. The silica gel with larger particle size was found to be better as the dosimeter filling because it enables better air circulation.

Unfortunately, to develop the dosimeter readings, it was necessary to heat the dosimeter up to $150^{\circ} \mathrm{C}$ for $1 \mathrm{~min}$ or to $100^{\circ} \mathrm{C}$ for $10 \mathrm{~min}$, or else leave it at $\mathrm{RT}\left(\mathrm{ca} .20^{\circ} \mathrm{C}\right)$ for $30 \mathrm{~min}$. It can seriously hamper the practical application of such a designed active smoking dosimeter.

\section{Application of TCMB and Pyridine Reaction Product (LI Complex) as a New Chromogenic Reagent for Analysis of Inorganic Compounds [20]}

LI Complex, a deep amaranth, polar, and well soluble in water compound (intensively red in water solutions) with a structure of $4 \mathrm{a}, 4 \mathrm{c}, 8 \mathrm{~b}, 12 \mathrm{~b}$-tetraazadibenzo $[a, f]$ indano $[1,2,3-c d]$ pentalene-4a,4c-diinium dichloride dihydrate (31), was found to change color in presence of some inorganic cations, affording complex compounds. Thus, it can be used as a chromogenic agent in analysis of inorganic salts as well. The highly colored complexes formation in presence of several inorganic anions were observed as well; it was obvious since LI Complex is a dication. In most cases, a high-colored complexes formation in presence of several inorganic anions was observed as well; it was obvious since LI Complex is a dication. In most cases, a high-colored precipitate formation occurred. The details are presented in Table 5.

An analytical importance can especially have reactions of LI Complex with silver (I) cation (purple coloration), mercury (II) dication (brown-red coloration), and lead (II) dication (red coloration, but a copious orange precipitate). 
TABLE 4: Colors and low detection limits (LOD) of the examined pesticides on TLC plates $[17,18]$.

\begin{tabular}{|c|c|c|c|c|c|}
\hline $\begin{array}{l}\text { Cmpd } \\
\text { no. }\end{array}$ & Common name & $\begin{array}{c}\text { Color (for } 10 \mu \mathrm{g} \text { in spot) } \\
(\text { Wavelength, } \mathrm{nm})\end{array}$ & $\begin{array}{l}\text { Detection limit } \\
\quad(\text { LOD, ng) }\end{array}$ & $\begin{array}{l}\text { Chromogenic } \\
\text { reaction/Evaluation }\end{array}$ & Type of pesticidal activity \\
\hline 39 & Nicotine & Yellow & $20 \pm 6$ & I/visually & Insecticide \\
\hline 40 & Pyrifenox & Brown & $25 \pm 4$ & I/visually & Fungicide \\
\hline 41 & Flurprimidol & Ochre-orange & $50 \pm 13$ & I/visually & Plant growth regulator \\
\hline 42 & Fenarimol & Yellow & $100 \pm 16$ & I/visually & Fungicide \\
\hline 43 & Prochloraz & Orange & 2000 & II/visually & Fungicide \\
\hline 44 & Bitertanol & Yellow & $1000 \pm 200$ & II/visually & Fungicide \\
\hline 45 & Paclobutrazol & Brownish & 10000 & II/visually & Fungicide \\
\hline 46 & Flutriafol & Orange & $1800 \pm 200$ & II/visually & Fungicide \\
\hline 47 & $\begin{array}{c}\text { Indol-3-ylacetic acid, } \\
\text { IAA }\end{array}$ & Brown,/460/ & $75 \pm 10$ & II/densitometry & Plant hormone \\
\hline 48 & $\begin{array}{l}\text { Indol-3-ylbutyric } \\
\text { acid, IBA }\end{array}$ & Brown-yellow,/460/ & $650 \pm 100$ & II/densitometry & Plant growth regulator \\
\hline 49 & Fenpiclonil & Brown-red,/498/ & $250 \pm 40$ & II/densitometry & Fungicide \\
\hline 50 & Ketoconazole & Ochre,/460/ & $120 \pm 15$ & II/densitometry & Fungicide \\
\hline 51 & Fluconazole & Yellow,/430/ & $490 \pm 60$ & II/densitometry & Fungicide \\
\hline
\end{tabular}

TABLE 5: Reactions of Complex LI ( $c=10 \mathrm{~g} / \mathrm{L}$ in water) with inorganic compounds $(c=100 \mathrm{~g} / \mathrm{L}$ in water).

\begin{tabular}{|c|c|c|c|c|c|}
\hline \multirow[t]{2}{*}{ No. } & \multirow[t]{2}{*}{ Compound } & \multicolumn{2}{|c|}{ Color of solution } & \multirow[t]{2}{*}{ Precipitate } & \multirow[t]{2}{*}{ After $24 \mathrm{~h}$} \\
\hline & & $\begin{array}{l}\text { Before LI Complex } \\
\text { addition }\end{array}$ & $\begin{array}{c}\text { After LI Complex } \\
\text { addition }\end{array}$ & & \\
\hline 1 & $\mathrm{CuSO}_{4} \cdot 5 \mathrm{H}_{2} \mathrm{O}$ & Blue & Dark-red & None & None \\
\hline 2 & $\mathrm{AgNO}_{3}$ & Colorless & Purple & Purple & $\begin{array}{c}\text { Purple precipitate, } \\
\text { solution over the } \\
\text { precipitate- } \\
\text { yellow-green }\end{array}$ \\
\hline 3 & $\mathbf{H g}\left(\mathrm{NO}_{3}\right)_{2} \cdot 1 / 2 \mathrm{H}_{2} \mathrm{O}$ & Colorless & Brown-red & Brown-red & $\begin{array}{l}\text { Brown-red } \\
\text { precipitate }\end{array}$ \\
\hline 4 & $\mathbf{O}=\mathrm{VSO}_{4}$ & Blue & Terra-Cotta & None & Green solution \\
\hline 5 & $\mathrm{Cr}\left(\mathrm{NO}_{3}\right)_{3}$ & Navy blue & Red, turbid & Orange & $\begin{array}{c}\text { Orange precipitate, } \\
\text { solution over the } \\
\text { precipitate- } \\
\text { reddish }\end{array}$ \\
\hline 6 & $\mathrm{Co}\left(\mathrm{NO}_{3}\right)_{2} \cdot 6 \mathrm{H}_{2} \mathrm{O}$ & Pink & Orange & Orange & No change \\
\hline 7 & $\mathbf{P b}\left(\mathrm{NO}_{3}\right)_{2}$ & Colorless & Red, turbid & Orange & $\begin{array}{c}\text { Orange precipitate, } \\
\text { solution over the } \\
\text { precipitate- } \\
\text { dark yellow }\end{array}$ \\
\hline 8 & $\mathrm{Na}_{4} \mathbf{P}_{2} \mathbf{O}_{7} \cdot 10 \mathrm{H}_{2} \mathrm{O}$ & Colorless & Navy blue & Navy blue & No change \\
\hline 9 & $\mathrm{NaIO}_{4}$ & Colorless & Bright yellow & Red & No change \\
\hline 10 & $\mathrm{~K}_{2} \mathrm{Cr}_{2} \mathrm{O}_{7}$ & Orange & Dark red & Dark red & No change \\
\hline 11 & $\mathrm{Na}_{2} \mathrm{CO}_{3}(\mathrm{pH} 10)$ & Colorless & Navy blue-green & $\begin{array}{l}\text { Slightly } \\
\text { turbid }\end{array}$ & $\begin{array}{l}\text { Navy blue } \\
\text { precipitate }\end{array}$ \\
\hline 12 & $\mathrm{NH}_{4} \mathrm{OH}(\mathrm{pH} 9)$ & Colorless & Brown-purple & Black-brown & No change \\
\hline 13 & $\mathrm{HCl}(\mathrm{pH} 1)$ & Colorless & Yellow & Pale orange & No change \\
\hline
\end{tabular}


Thus, this chromogenic agent can be applied as a complexometric indicator in solutions as well as an adsorption indicator (colored precipitates formation). Some anions (e.g., pyrophosphates, periodates, or dichromates) may also produce high-colored products with LI Complex.

Color change after addition of water solutions of $\mathrm{Na}_{2} \mathrm{CO}_{3}, \mathrm{NH}_{4} \mathrm{OH}$, and $\mathrm{HCl}$ of various $\mathrm{pH}$ allows to suppose that LI Complex may also be used as a sensitive indicator in acid-base titration. Indeed, we have found that this method may have the following well-established titration parameters.

(i) The aqueous LI-Complex should be used at concentrations 3 to $10 \mathrm{~g} / \mathrm{L}$ water.

(ii) The colors of indicator were as follows: yellow in acidic solutions and brown-purple in the basic ones, and the intermediate colors were orange-pink and red.

(iii) Since LI Complex is a dication, there are two transition points during the titration.

(iv) The color transition points were found:

(a) at weakly acidic $\mathrm{pH}$ region (4 to 4.5 , from yellow into yellow-pink),

(b) at neutral region ( $\mathrm{pH} 6.5$ to 7 ), from orangepink into red.

\section{Conclusions}

LI Complex is the main product of reaction of 2-trichloromethylbenzimidazole (TCMB, 1) with pyridine, the simplest and the most representative example of series of reactions described in this paper. In this reaction, a complex and difficult to identify high-colored mixture of polar compounds is formed, and the reaction seems to be very specific and regioselective. The structure of the LI Complex main component was established as $4 \mathrm{a}, 4 \mathrm{c}, 8 \mathrm{~b}, 12 \mathrm{~b}$-tetraazadibenzo $[a, f]$ indano $[1,2,3-c d]$ pentalene-4a,4c-diinium dichloride dihydrate (31).

This reaction was subsequently used to develop a package of analytical methods in both organic and inorganic chemistry. As its main application, TCMB showed to be a sensitive and specific chromogenic agent to visualize and determine some organic compounds on TLC plates: azines, azoles, benzazoles, $o$-phenylenediamines, and heteroaromatic pesticides (also with scanning spectrodensitometry of developed TLC plates). The mechanisms of two different chromogenic reactions of TCMB with azines and azoles were proposed and proved. The attempts to apply one of the aforementioned methods to develop passive and active nicotine dosimeters were also discussed. Finally, the applications of the LI Complex for analysis of inorganic cations and another application of this reagent as an indicator in acid-base titration were presented.

Nonetheless, the bunch of methods developed about the triangle TCMB-pyridine-LI Complex has its limitations. TCMB may be used as a chromogenic agent mainly in TLC, which is often considered to be only a semiquantitative method, not frequently used by analytical chemists (but it is commonly used by synthetic organic chemists for control the reaction progress on TLC plates, and they are also the target of this paper). Moreover, the color reactions in most cases should be accelerated at high temperature, usually at $100-150^{\circ} \mathrm{C}$ for several minutes, and it makes the analytical procedures more complicated.

However, there are not many analytical methods as universal as the ones described previously. These methods were quoted in many publications, for instance, [21-30]. Moreover, TCMB may be easily synthesized from commercially available methyl trichloroacetimidate and $o$-phenylenediamine [1].

\section{References}

[1] G. Holan, E. L. Samuel, B. C. Ennis, and R. W. Hinde, "2-trihalogenomethylbenzazoles. I. Formation," Journal of the Chemical Society C, vol. 1967, pp. 20-25, 1967.

[2] G. Holan and E. L. Samuel, "2-Trihalogenomethylbenzazoles. Part II. Reactions of 2-trihalogenomethylbenzimidazoles with Ammonia and Amines," Journal of the Chemical Society, vol. 1967, pp. 25-29, 1967.

[3] B. C. Ennis, G. Holan, and E. L. Samuel, "2-trihalogenomethylbenzazoles. IV. Reactions with difunctional nucleophiles. Formation of heterocyclic rings on the 2-position of benzazoles," Journal of the Chemical Society, vol. 1967, pp. 33-39, 1967.

[4] B. C. Ennis, G. Holan, and E. L. Samuel, "2-trihalogenomethylbenzazoles. 3. Reactions of 2-trichloromethylbenzimidazole with nucleophiles," Journal of the Chemical Society, vol. 1967, pp. 30-33, 1967.

[5] L. Konopski and B. Jerzak, "2-Trichloromethylbenzimidazole, a new selective chromogenic reagent for the detection of some azines on thin-layer plates," Journal of Chromatography A, vol. 363, no. 2, pp. 394-396, 1986.

[6] L. Konopski and E. Pawlowska, "2-Trichloromethylbenzimidazole as a selective chromogenic reagent for the detection of some azoles on thin-layer plates," Journal of Chromatography A, vol. 669, no. 1-2, pp. 275-276, 1994.

[7] L. Konopski and A. Kiełczewska, "2-Trichloromethylbenzimidazole, a new dyeing reagent for thin layer chromatographychromogenic reactions with five-membered heteroaromatic compounds with condensed benzene ring," Chemia Analityczna, vol. 40, pp. 887-895, 1995.

[8] L. Konopski, "Mechanisms of chromogenic reactions of 2 trichloromethylbenzimidazole with nitrogen containing heteroaromatic compounds," ORGANIKA-Prace Naukowe Instytutu Przemysłu Organicznego, vol. 1995, pp. 25-32, 1995.

[9] L. Konopski and B. Jerzak, "2-Trichloromethylbenzimidazole, a selective chromogenic reagent for the detection of some azines on thin-layer plates. Addendum," Journal of Chromatography A, vol. 481, pp. 477-479, 1989.

[10] I. Ya. Postovskii, V. P. Mamaev, G. A. Mokrushina, O. A. Zagulaeva, and M. A. Kosareva, "Benzimidazolnye proizvodnye s zvitterionnym stroenyem (Benzimidazole derivatives with a zwitterion structure)," Khimya Geterotziklicheskikh. Soedinenii, vol. 1975, pp. 987-989, 1975.

[11] K. Fujiwara, "New reaction for the detection of chloroform," Sitzungsberichte und Abhandlungen der Naturforschenden Gesellchaft zu Rostock, vol. 6, pp. 33-43, 1916.

[12] T. Uno, K. Okumura, and Y. Kuroda, "Mechanism of the Fujiwara reaction: structural investigation of reaction products 
from benzotrichloride," Journal of Organic Chemistry, vol. 46, no. 16 , pp. 3175-3178, 1981.

[13] C. I. F. Watt, "Hydride Shifts and Transfers," Advances in Physical Organic Chemistry, vol. 24, pp. 57-112, 1988.

[14] G. M. Badger, B. C. Ennis, and W. E. Matthews, "DroebnerMiller, Skraup and related reactions. II. Preparation and cyclization of 3-methyl-4-(2-nitroanilino)-2-butanone," Australian Journal of Chemistry, vol. 16, no. 5, pp. 828-832, 1963.

[15] L. Konopski, "2-Trichloromethylbenzimidazole, a selective chromogenic reagent for the detection of $o$-phenylenediamine on thin-layer plates," Journal of Chromatography, vol. 541, no. 1-2, pp. 480-482, 1991.

[16] F. Cramer, K. Pawelzik, and H. J. Baldauf, "Imidoester. I. Darstellung von trichloroacetimidsäureestern (Imido esters. I. Preparation of trichloroacetamidic acid esters)," Chemische Berichte, vol. 91, pp. 1049-1054, 1958.

[17] L. Konopski, "2-trichloromethylbenzimidazole, a new selective chromogenic reagent for detection of some heteroaromatic pesticides on thin-layer chromatographic plates," Pesticide Science, vol. 41, pp. 335-338, 1994.

[18] L. Konopski and T. Potocka-Smolka, "The simple and sensitive densitometric method for detection of some heteroaromatic pesticides on TLC plates using 2 trichloromethylbenzimidazole as chromogenic reagent," Pestycydy, vol. 1997, no. 1-2, pp. 33-38, 1997.

[19] L. Konopski, E. Pawłowska, and H. Konopka, "2-Trichloromethylbenzimidazole, a new selective reagent for detection of some heterocyclic compounds on thin-layer plates," Raport of Grant No. 2260292 02, Scientific Research Committee of Poland, No. 2260292 02, 1993.

[20] A. Kiełczewska and L. Konopski, "Studies on application of reaction product between 2 trichloromethylbenzimidazole and pyridine (LI Complex) as a new chromogenic agent in analysis of in organic compounds," ORGANIKA-Prace Naukowe Instytutu Przemystu Organicznego, vol. 1995, pp. 33-43, 1995.

[21] J. Sherma, "Thin-layer and paper chromatography," Analytical Chemistry, vol. 60, no. 12, 1988.

[22] J. Sherma, "Pesticides," Analytical Chemistry, vol. 67, no. 12, pp. 1R-20R, 1995.

[23] J. Sherma, "Planar chromatography," Analytical Chemistry, vol. 70, no. 12, pp. 1R-19R, 1998.

[24] J. Sherma, "Planar chromatography," Analytical Chemistry, vol. 70, no. 12, pp. 7R-26R, 1998.

[25] J. Sherma, "Determination of pesticides by thin-layer chromatography," Journal of Planar Chromatography, vol. 10, no. 2, pp. 80-89, 1997.

[26] J. Sherma, "Recent advances in thin-layer chromatography of pesticides," Journal of AOAC International, vol. 82, no. 1, pp. 48-53, 1999.

[27] K. J. Krost, "Analysis of selected chemical groups by liquidchromatography mass-spectrometry," Applied Spectroscopy, vol. 47, no. 6, pp. 821-829, 1993.

[28] "Planar chromatography," Journal of Chromatography, vol. 412, no. 1, pp. B95-B111, 1987.

[29] J. Sherma, "Planar chromatography," Analytical Chemistry, vol. 64, no. 12, pp. R134-R147, 1992.

[30] Y. Wang, G. Yao, P. Zhu, and X. Hu, "Indirect biamperometric determination of $o$-phenylenediamine in lab-on-valve format using reversible indicating redox system," Analyst, vol. 136, no. 4, pp. 829-834, 2011. 


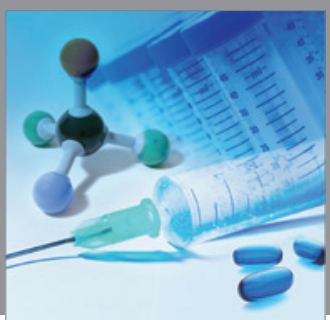

International Journal of

Medicinal Chemistry

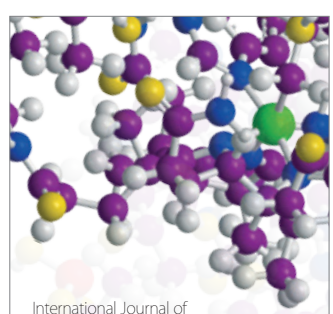

Carbohydrate Chemistry

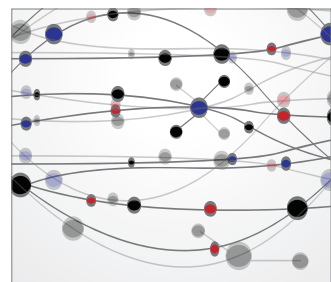

The Scientific World Journal
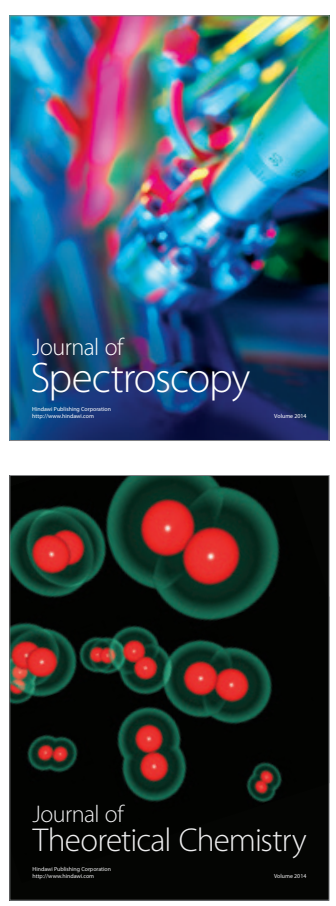
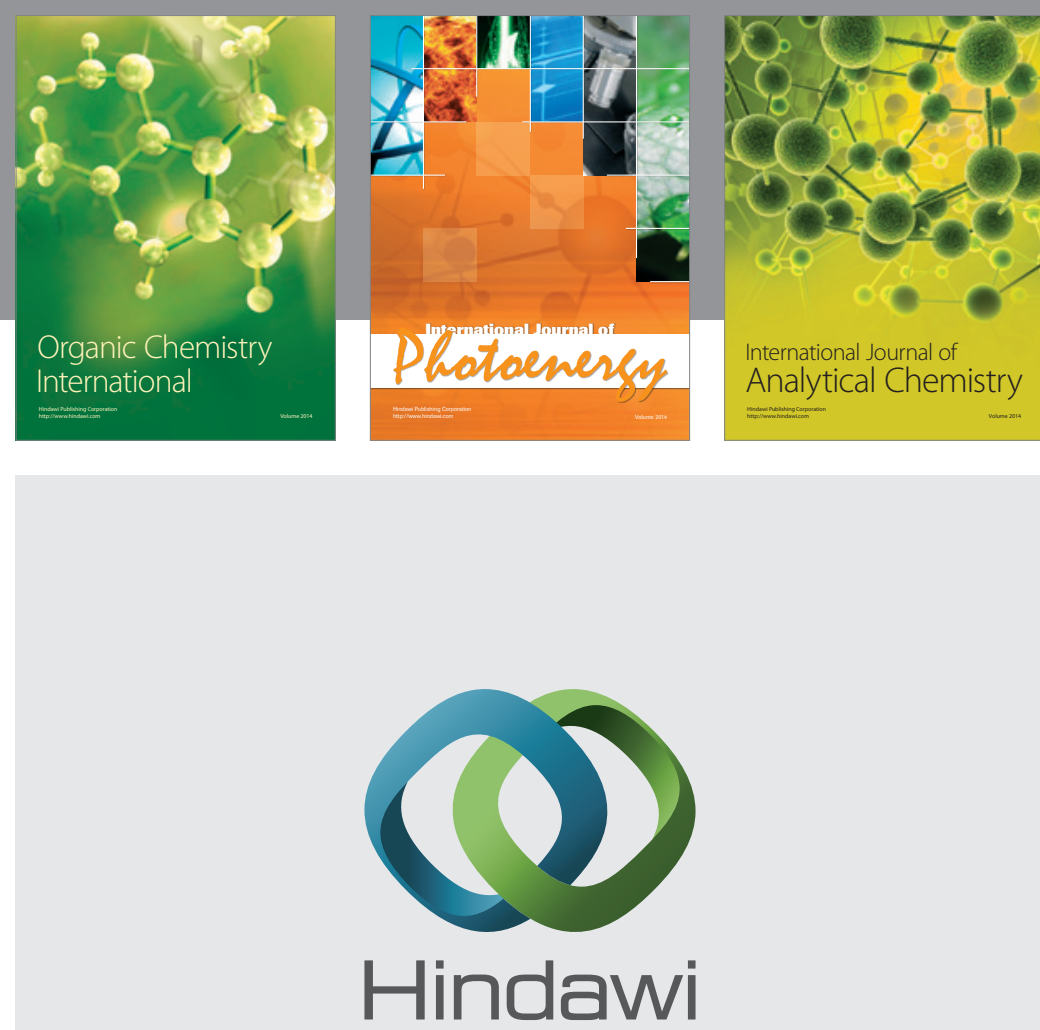

Submit your manuscripts at

http://www.hindawi.com
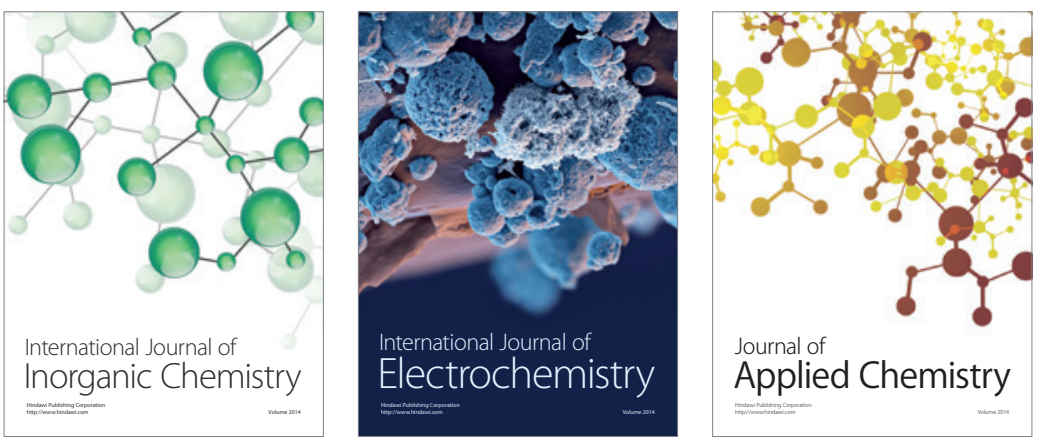

Journal of

Applied Chemistry
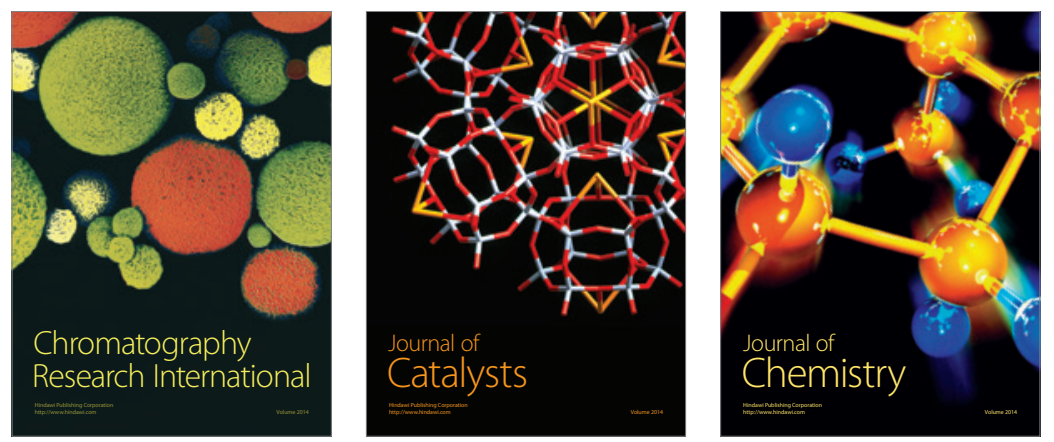
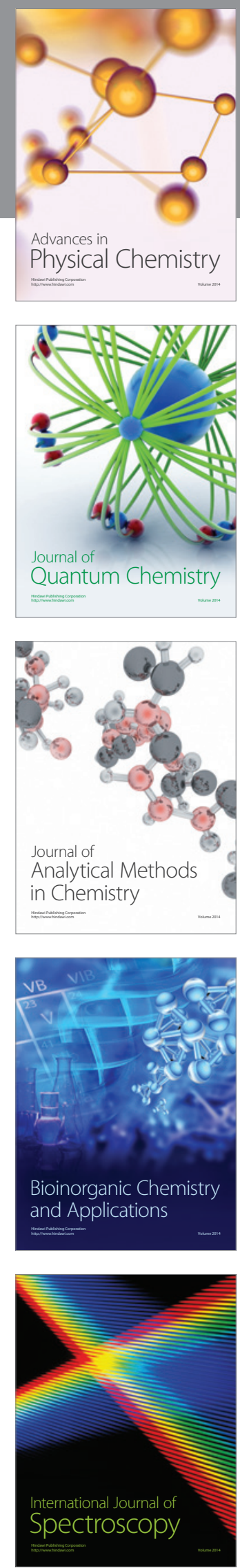